\title{
Detection of Colletotrichum coccodes causing leaf anthracnose on Pisum sativum in southern Brazil
}

\author{
Cristiano Bellé ${ }^{1}$ (D) Rodrigo Ferraz Ramos $^{1} \cdot$ Renata Moccellin $^{2} \cdot$ Cândida Renata Jacobsen de Farias ${ }^{2}$
}

Received: 23 June 2019 / Accepted: 31 August 2019 / Published online: 5 September 2019

(C) Società Italiana di Patologia Vegetale (S.I.Pa.V.) 2019

Keywords Detection $\cdot$ Anthracnose $\cdot$ Pea $\cdot$ Colletotrichum $\cdot$ Pathogenicity

Leaf samples from pea plants (Pisum sativum L.) (cv. Telefone Alta) showing typical anthracnose symptoms of circular to oval brown spots were collected in September 2017 from commercial fields in Frederico Westphalen, Rio Grande do Sul state, Brazil. Samples of the leaf lesions were surfacesterilized, placed on potato-dextrose agar, and incubated at $25^{\circ} \mathrm{C}$. The resulting colonies were circular and initially white, becoming dark with age. Aerial mycelia were sparse and white, with profuse production of microsclerotia. The conidia were oval, had smooth walls, rounded ends, a slight central constriction, and sometimes a papillate basal scar. They measured $(n=100)(16-) 18.9(-20.7) \times(3.8-) 4.5(-5.2) \mu \mathrm{m}$ and were similar to those described in Colletotrichum sp. To confirm its taxonomy, the ITS, TUB2, ACT, and GAPDH genes were analysed with the method of Weir et al. (2012). BLAST searches showed 99\%-100\% identity with reference sequences of C. coccodes, including ex-type CBS 369.75, and CBS 125.57 (ITS: HM171679, TUB2: JQ005859, ACT: HM171667, and GAPDH: JX546727). The specimen was deposited in the Federal University of Pelotas Herbarium (LPS01-30). The DNA sequences obtained were submitted to GenBank (accession Nos. ITS: MH793508, TUB2: MH800202, ACT: MH800203 and GAPDH:

Cristiano Bellé

crbelle@gmail.com

1 Universidade Federal de Santa Maria, Centro de Ciências Rurais, Departamento de Solos, Santa Maria, Rio Grande do Sul 97105-900, Brazil

2 Universidade Federal de Pelotas, Faculdade de Agronomia Eliseu Maciel, Departamento de Fitossanidade, Capão do Leão, Rio Grande do Sul 96010-900, Brazil
MH800204).To confirm Koch's postulates, 10 P. sativum plants (cv. Telefone Alta) were inoculated with a spore sus-

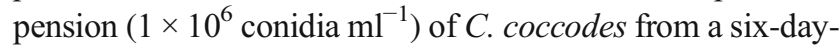
old culture. After inoculation, the plants were covered with plastic bags to maintain a high relative humidity, incubated at $25^{\circ} \mathrm{C}$, and monitored daily for symptom development. Plants treated with sterile water were used as controls. Four days after inoculation, the leaves displayed symptoms similar to those observed in the field, whereas the controls remained symptomless. The experiment was repeated. Cultures reisolated from inoculated leaves had the same morphological and molecular traits as the initial isolates. To our knowledge, this is the first report of $C$. coccodes associated with pea anthracnose in Brazil or elsewhere.

\section{Compliance with ethical standards}

Conflict of interest The authors declare that they have no conflict of interest.

Ethical approval This article does not contain any studies with human participants or animals performed by any of the authors.

Informed consent Informed consent was obtained from all individual participants included in the study.

\section{Reference}

Weir BS, Johnston PR, Damm U (2012) The Colletotrichum gloeosporioides species complex. Stud Mycol 73(3):115-180

Publisher's note Springer Nature remains neutral with regard to jurisdictional claims in published maps and institutional affiliations. 